\title{
Os pilares da liderança e o modelo situacional: a influência do líder na formação de equipes de alta performance e nos resultados
}

\author{
Márcio Marins" \\ Paula Elisângela Martins" \\ Cássia Aparecida Pasqual ${ }^{* * * *}$

\section{Resumo}

Este artigo tem o objetivo identificar os modelos de liderança utilizados pelas empresas General Sports Ltda. e General Surf Ltda., com base na Teoria da Liderança Situacional e nos Quatro Pilares da Liderança, e também de estabelecer um comparativo entre os efeitos desses modelos, para, por fim, analisar o impacto de como distintas formas de liderança podem influenciar nos resultados organizacionais e no desempenho de suas equipes. Para isso, a metodologia utilizada foi um estudo de caso dividido em três etapas: a observação direta e enquadramento do modelo de liderança aplicado por cada um dos gestores de vendas das empresas na Teoria da Liderança Situacional, a análise documental sobre os resultados financeiros e os índices de turnover das suas equipes e, finalmente, o comparativo entre as empresas para ambos os indicadores. Como resultados principais, pode-se constatar que o modelo de liderança tradicional, baseado no modelo de comando e controle, foi responsável pelo aumento no índice de rotatividade e pela redução nos resultados financeiros da General Sports Ltda. Em contrapartida, verificou-se que práticas de liderança voltadas ao compartilhamento do conhecimento e à delegação das atividades, adotadas pela gestão da General Surf Ltda., possibilitaram aumento no desempenho organizacional e individual.

Palavras-chave: Liderança Situacional. Quatro Pilares da Liderança. Equipes de alto desempenho.

* Mestrando em Informática na Educação pelo Instituto Federal do Rio Grande do Sul. MBA em Economia e Gestão Empresarial pela Universidade de Passo Fundo. Bacharel em Administração de Empresas, habilitação Comércio Exterior. Professor de Gestão e Negócios nos cursos de graduação e MBA da Fundação Getúlio Vargas/FTEC. E-mail: marciomarins@ftec.com.br

* Pós-graduada em Gestão Empresarial pela Universidade do Vale do Rio dos Sinos. Tecnóloga em Gestão de Recursos Humanos pela Faculdade Anglo-Americano de Caxias do Sul. E-mail: obox.br@ gmail.com

*** Mestre em Agronegócios pela Universidade Federal do Rio Grande do Sul. Professora da Faculdade de Ciências Econômicas, Administrativas e Contábeis da Universidade de Passo Fundo. E-mail: cpasqual@upf.br

http://dx.doi.org/10.5335/rtee.v22i46.6759

Submissão: 05/05/2015. Aceite: 16/05/2016. 


\section{Introdução}

Atualmente, além de constantes, as mudanças mercadológicas estão acontecendo de forma consideravelmente mais aceleradas. Dia após dia, os gestores estão tendo consciência de que as pessoas são o bem mais valioso que possuem e que eles, como líderes, precisam estar bem preparados para exercer eficazmente essa função. Porém, nem todos os gestores estão aptos para o cargo, dado que muitos ainda têm a ideia errônea de que, "manda quem pode, e obedece quem precisa", contradizendo as mudanças exigidas nos modelos de gestão e no perfil da liderança na nova economia. O modelo tradicional de liderança, já considerado ultrapassado, é desfavorável para as organizações, pois inibe a criatividade e a inovação dos liderados. Empresas que utilizam boas práticas de gerenciamento de pessoas, além de estimular a integração entre os liderados, faz com que adquiram vantagens competitivas em relação a seus concorrentes. O grande desafio da nova liderança é identificar e explorar as habilidades e singularidades dos liderados, conduzindo-os, eficientemente ao sucesso.

Liderar significa reinventar-se diariamente, ou seja, ser líder é saber que o aprendizado é vitalício. Pode-se dizer, então, que o líder precisa estar aberto às mudanças, agindo de acordo com as situações apresentadas dia após dia. Assim como as organizações, um número cada vez maior de indivíduos terá que desenvolver aptidões para se enquadrar no perfil do líder do século XXI (KOTTER, 1997). Nesse sentido, a aplicação do estilo Liderança Situacional proporciona elementos que influenciam os resultados dos times, fazendo com que seus integrantes se sintam peças-chave no alcance dos objetivos organizacionais, ao mesmo tempo que potencializa o surgimento de equipes de alto desempenho (NOVO; CHERNICHARO; BARRADAS, 2008).

$O$ presente artigo tem o objetivo identificar os modelos de liderança, com base na Teoria da Liderança Situacional e nos Quatro Pilares da Liderança, utilizados pelas empresas General Sports Ltda. e General Surf Ltda. companhias pertencentes à Surf Company Ltda., grupo empresarial varejista localizado no sul do país - e que neste estudo terão suas identidades mantidas em caráter de sigilo a fim de preservar seus diferenciais estratégicos. Além disso, ao estabelecer um comparativo entre os efeitos desses modelos, pretende-se analisar o impacto de como distintas formas de liderança podem influenciar nos resultados organizacionais e no desempenho de suas equipes.

O presente artigo está dividido da seguinte maneira: na seção 2, é apresentado o modelo teórico a respeito da liderança e seus estilos, do desempenho empresarial, dos Quatro Pilares da Liderança e da escassez de líderes no mercado. Na seção 3, apresenta-se o método utilizado no estudo de caso. $\mathrm{Na}$ seção 4, a análise dos dados, primeiramente, identificando-se o modelo de gestão utilizado pelas empresas 
segundo a Teoria Situacional e os Quatro Pilares da Liderança, verificando-se o índice de turnover da General Sports Ltda. e da General Surf Ltda. e, posteriormente, fazendo um parâmetro entre os resultados financeiros e per capita das empresas objeto do estudo. Por fim, na última seção, são apresentadas as principais conclusões obtidas no decorrer da análise.

\section{Referencial teórico}

\section{$2.1 \mathrm{O}$ conceito de liderança e a sua influência na formação de equipes de alta performance}

Para Chiavenato (2006), a liderança é o processo de exercer influência sobre pessoas ou grupos nos esforços para realização de objetivos em uma determinada situação. Na visão de Bergamini (1994), o mesmo conceito trata da capacidade de um indivíduo - aqui tido como o líder - de influenciar um grupo em direção a um determinado objetivo, assegurando que os liderados compreendam as metas da organização e os caminhos a serem trilhados para atingi-los. Covey (1996) complementa ao afirmar que os líderes eficazes "transformam" pessoas e organizações, promovem mudanças em suas mentes e em seus corações, ampliam a sua visão e a sua compreensão, esclarecem as metas, tornam os comportamentos congruentes e consonantes com as crenças, os princípios e os valores e, ainda, implementam transformações permanentes que se autoperpetuam e cujo ímpeto e intensidade são cada vez maiores. Para Goleman (2010), os melhores executivos devem alternar entre seis tipos distintos de liderança, conforme mostra o Quadro 1.

Quadro 1 - Os seis tipos distintos de liderança

\begin{tabular}{|c|c|c|c|}
\hline Tipo & Característica & $\begin{array}{l}\text { Impacto } \\
\text { organizacional }\end{array}$ & Definição em uma frase \\
\hline Despótico & $\begin{array}{l}\text { Exige cumprimento imediato de } \\
\text { ordens. }\end{array}$ & Negativo & Faça o que eu mando! \\
\hline Visionário & Mobiliza todos rumo a uma visão. & Positivo & Venha comigo! \\
\hline Agregador & $\begin{array}{l}\text { Cria harmonia e estabelece vínculos } \\
\text { emocionais. }\end{array}$ & Positivo & Primeiro, as pessoas! \\
\hline Democrático & $\begin{array}{l}\text { Consegue o consenso por meio da } \\
\text { participação. }\end{array}$ & Positivo & Qual a sua opinião? \\
\hline Agressivo & $\begin{array}{l}\text { Estabelece altos padrões de } \\
\text { desempenho. }\end{array}$ & Negativo & Faça como eu faço, já! \\
\hline Conselheiro & Prepara as pessoas para o futuro. & Positivo & Tente isso! \\
\hline
\end{tabular}

Fonte: elaborado pelos autores com base em Golemann (2010). 
Embora os seis estilos não pareçam diretamente relacionados, o autor aponta que cada um desses direcionamentos pode ser assumido de acordo com cada situação estabelecida. A visão de Maximiano (2005) acrescenta que são dois os estilos predominantes de liderança, sendo que o primeiro - o autocrático - centraliza o poder de decisão no chefe, enquanto o segundo - o democrático - permite a participação dos liderados no processo de decisão ou de uso da autoridade por parte do dirigente. A eficácia do estilo de liderança depende de seu efeito sobre o desempenho da tarefa e a satisfação do influenciado, seja ele indivíduo ou grupo. Se o influenciado mostrar-se satisfeito e, ao mesmo tempo, apresentar desempenho satisfatório, o estilo é eficaz.

Nesse sentido, Fuhrmeister (2011) esclarece que essa influência exercida pelo líder leva-o ao papel de formador de equipes de alta performance. Esse conceito de gestão compreende três práticas importantes: o feedback, o compartilhamento dos norteadores da organização e o incentivo ao empowerment. Um feedback aberto e honesto entre os integrantes da equipe e sua liderança torna-se a "linha mestra" de rápido desenvolvimento e produção de resultados efetivos. Por meio dessa ferramenta, os integrantes da equipe de alta performance conseguem atingir a melhoria constante. Já o compartilhamento dos norteadores (missão, visão e valores) da organização sinaliza o objetivo macro a que essa equipe se propõe - é o direcionamento principal. Outra característica importante é o empowerment, em que os integrantes da equipe são estimulados a trazer sua inteligência para o trabalho e usarem seu conhecimento, experiência e motivação para criar resultados saudáveis.

A construção de equipes autônomas, autogeridas, empoderadas e excelentes requer a presença de um novo executivo: aquele que em vez de gerenciar as pessoas, gerencia com as pessoas. Embora enfatize-se que uma equipe para atingir a plena eficiência recisa seguir algumas premissas, conforme mostra o Quadro 2, times coesos requerem líderes renovadores que incentivam e impulsionam, agindo como verdadeiros coaches que preparam, desenvolvem e projetam as pessoas ao mesmo tempo que abrem novos horizontes e oportunidades (CHIAVENATO, 2005, 2008). 
Quadro 2 - Os seis tipos distintos de liderança

\begin{tabular}{|l|l|}
\hline Objetivos claros & $\begin{array}{l}\text { Tanto a missão como os objetivos da equipe, e os objetivos individuais de } \\
\text { cada membro da equipe, devem ser claramente definidos e aceitos por } \\
\text { todos os membros. } \\
\text { Os participantes da equipe devem ter uma percepção conjunta e coerente } \\
\text { da situação em que se encontram, o que ajuda a visualizar os problemas, } \\
\text { definir seus propósitos e integrar suas atividades. } \\
\text { Os membros da equipe devem ser alocados de acordo com o seu perfil, } \\
\text { as suas habilidades, as suas competências e o seu tipo de personalidade, } \\
\text { pois poderão ser mais eficientes. } \\
\text { Todos da equipe precisam opinar e o compromisso deve ser alcançado por } \\
\text { grupal } \\
\text { meio da discussão e do consenso espontâneo entre os membros para que } \\
\text { as decisões se tornem colaborativas. } \\
\text { As funções de liderança da equipe devem passar de pessoa para pessoa, } \\
\text { dependendo da situação, necessidades da equipe e dos membros. }\end{array}$ \\
$\begin{array}{l}\text { Liderança } \\
\text { compartilhada }\end{array}$ & $\begin{array}{l}\text { A equipe aceita o desacordo como uma maneira de discutir novas ideias e } \\
\text { resolver seus assuntos de maneira criativa e inovadora. } \\
\text { povas ideias } \\
\text { problemas a solução de }\end{array}$ \\
$\begin{array}{l}\text { Avaliação da } \\
\text { eficácia }\end{array}$ & $\begin{array}{l}\text { lizando as tarefas e as atividades, como estão alcançando metas e como } \\
\text { está se construindo e mantendo relacionamentos eficientes entre os mem- } \\
\text { bros. }\end{array}$ \\
\hline
\end{tabular}

Fonte: elaborado pelos autores com base em Chiavenato (2008).

O modelo de liderança construído em torno do conceito de "alto desempenho", compreende sistematicamente o time e cada "universo pessoal" inserido nele. Tal compreensão contribui para que a liderança mantenha todos motivados e comprometidos com as metas estabelecidas pela organização ao mesmo tempo que toma decisões acertadas, define claramente o papel de cada integrante da equipe, delegando deveres e autoridade, dentro dos padrões individuais e adequados.

\subsection{O modelo Liderança situacional}

Dentro da teoria geral da administração, pode-se dizer que Taylor era, de certa forma, descrente do ser humano, pois acreditava que o chefe deveria controlar de forma absoluta seus subordinados, enfatizar a importância do aumento e da eficiência da produtividade, com ênfase nas tarefas e não nas pessoas. Eis que surge o princípio da exceção, no qual o líder deveria exercer o controle quando algo não ocorria de maneira satisfatória, pois, do contrário, jamais elogiaria um trabalho bem feito ou daria atenção demasiada aos fatos. No entanto, na administração 
clássica, Fayol passou a dar maior ênfase à estrutura e aos processos organizacionais, minimizando a especialização e aumentando a "horizontalização da gestão". Os níveis hierárquicos foram reduzidos e o gerente passou a ser multifuncional, uma vez que o surgimento da departamentalização obrigou a liderança a conhecer áreas afins que estaria liderando (CHIAVENATO, 2011).

Segundo Bergamini (1994), a liderança já não possui mais sua ênfase colocada unicamente sobre uma variável isolada circunscrita à ação do líder sobre um tipo de atitude passiva do subordinado. A liderança é estudada como um processo de interação que envolve trocas sociais, sendo que, nesse caso, o líder é visto como alguém que traz benefícios não apenas ao grupo. Cada membro em particular é alvo desse intercâmbio. Em troca, os membros do grupo devolverão ao líder seu reconhecimento e aceitação como forma de lhe conferir a autoridade para dirigir pessoas.

De acordo com Castro (2013), devido à globalização, às novas tecnologias e às mudanças que estão ocorrendo no mercado de trabalho, percebeu-se a importância de utilizar novos modelos de gestão, em que o líder saiba oferecer um feedback adequado e seja capaz de valorizar as diferenças existentes na sua equipe de trabalho. Para Tonet et al. (2012), não existe um único estilo de liderança válido. A aplicação dependerá das circunstâncias. Contudo, é preciso ratificar que a liderança é uma relação recíproca, logo, não existe líder sem liderados. O comportamento do líder é importante, mas o comportamento e a maturidade dos liderados são elementos para se estar atento.

A Liderança Situacional baseia-se em uma inter-relação entre a quantidade de orientação e direção que o líder oferece e a quantidade de apoio socioemocional (dado pelo líder) e o nível de prontidão (maturidade) dos subordinados no desempenho de uma tarefa, função ou objetivo específico. Trata-se da percepção da não existência de um único modo de influenciar ou gerir pessoas, pois o estilo de liderança que um gestor deve adotar, com indivíduos ou grupos, depende, também, do nível de maturidade das pessoas que esse líder deseja influenciar (HERSEY; BLANCHARD, 1986).

A chave da Liderança Situacional está na relevância de o líder ser capaz de mudar o estilo combinando, justamente, o grau de maturidade dos liderados e as situações cotidianas vivenciadas na organização. É preciso ressaltar que esses dois elementos estão sempre diretamente ligados ao ser aplicada essa teoria, mas cabe ao líder identificar e levar em conta o grau de experiência dos liderados para que o estilo de liderança mais adequado possa ser aplicado ao mesmo tempo que um comportamento de gestão mais flexível possa ser desenvolvido (NOVO; CHERNICHARO; BARRADAS, 2008). A Figura 1 apresenta a relação da liderança com os quesitos delegação, apoio, treinamento e direcionamento. 
Figura 1 - O modelo da Liderança Situacional

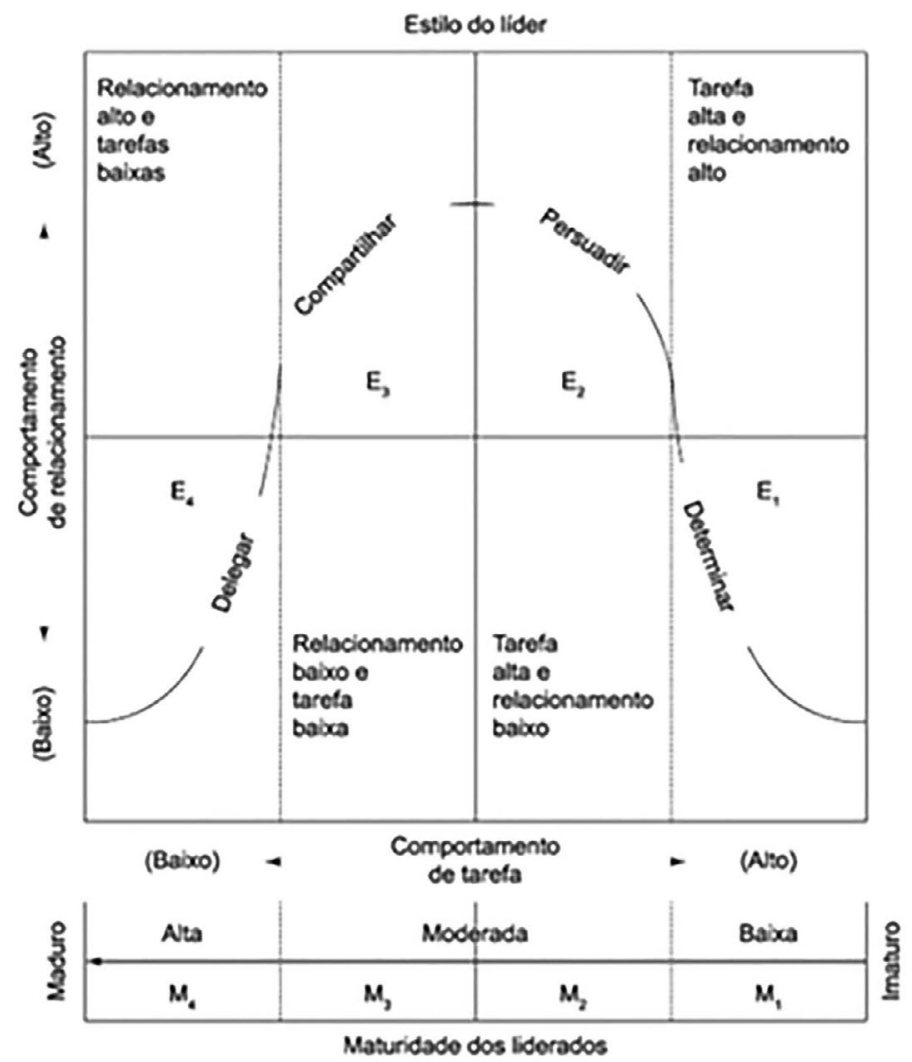

Fonte: HERSEY; BLANCHARD, 1986, p. 189.

O modelo em questão mostra diferentes combinações que demonstram os estilos do líder - desde o seu relacionamento com a equipe e seu foco na tarefa - e o grau de maturidade dos liderados. Assim, um líder pode adotar um comportamento unicamente determinador (mais voltado para a tarefa) ou optar por um comportamento de relacionamento, mais lógico-racional (persuasivo), sem abrir mão da determinação de atividades, minimizando a resistência e diminuindo a possibilidade de erros na obtenção de resultados (E1) para o caso de ele estar gerindo uma equipe muito nova, logo, com pouca maturidade de conjunto ou experiência (M1). O oposto também pode ocorrer, uma vez que o alto relacionamento com a equipe permite a adoção de um comportamento mais compartilhador e delegador (E4) na medida em que a equipe possui maior espírito de conjunto e experiência, tornando-se mais madura (M4). 
Fica claro que o nível de prontidão dos membros de uma equipe é que aponta o caminho que o líder deve seguir. À medida que tal nível cresce, o líder é mais orientado ao relacionamento do que para a tarefa, motivando a equipe a desenvolver com maior motivação e entusiasmo suas atividades. Isso é passível de ocorrer em modelos mais flexíveis, quando, à medida que as habilidades de execução dos integrantes do grupo vai aumentando, eles necessitam cada vez menos de orientação - o reconhecimento é o grande gatilho de motivação para manter bons resultados. O contrário também é possível identificar, já que à medida que a equipe precisa ser desenvolvida, maiores serão os comportamentos orientados para a tarefa, enfatizando maior interferência do líder em ações de acompanhamento e controle - como o que ocorre em modelos de gestão mais conservadores (FRANCO, 2008).

\subsection{Os Quatro Pilares da Liderança do século XXI}

Em uma era em que a tecnologia e novas formas de comunicação surgem e avançam rapidamente, gerenciar pessoas é visto cada vez menos como algo atrelado a um grande sistema. Muitas organizações consideram as pessoas como o eixo central de todo o processo organizacional, e é nesse contexto que o conceito de liderança passa a "gestão de patrimônio". O líder tem traços pessoais singulares que o tornam especial e diferente e que, ainda, permitem que as pessoas ao seu redor o percebam como tal (SANTOS et al., 2013).

Para George (2009), o líder precisa ser autêntico, saber deixar o ego de lado, ouvir sempre e de coração aberto, criando um ambiente de reciprocidade e harmonia. Além disso, a espiritualidade e a fé são colocadas como características importantes para um líder, pois o autor enfatiza que a busca pelo equilíbrio entre o lado pessoal e profissional é de suma importância para que esse gestor tenha uma vida e uma liderança saudável. O líder precisa estar comprometido a fazer um mundo melhor e a liderar não só com a mente, mas também com o coração. Isso vai ao encontro da qualidade essencial de um líder: ser ele mesmo, autêntico sob qualquer ponto de vista, jamais concordando com algo que não condiz com os seus verdadeiros valores - o que significa, muitas vezes, aprender a lidar com a solidão do comando e não ser influenciado pela pressão dos demais.

As organizações consideradas modernas e atuais já não têm mais líderes unicamente atrelados aos cargos, tornando o papel da liderança algo mais difuso, leve, fazendo com que, assim, tais organizações necessitem cada vez mais de gestores com maior nível de competência em função do desenvolvimento de um novo tipo de gestão (STEPANSK; COSTA, 2012). Organizações de sucesso prezam por um 
modelo de gestão eficiente e eficaz, adotando ações coerentes na condução dos processos, o que passa, também, por um alinhamento estratégico adequado às particularidades da organização e do seu campo de atuação (DALMAN; TOSTA, 2009).

A liderança do século XXI precisa exercer de forma efetiva pilares essenciais. O primeiro pilar, o alinhamento, trata do papel do líder no direcionamento para a equipe, fazer com que seus membros entendam a missão, a visão e os valores da empresa, e uma vez entendidos, que sejam capazes de auxiliar na tomada de decisões. Para isso é necessário que a equipe realmente tenha confiança nesses valores e perceba que eles são vivenciados por todos da empresa, principalmente pelo seu líder (GEORGE, 2009).

De acordo com Maxwell (2012), as lideranças passam a adquirir maior sabedoria ao perceber que não conseguem realizar tudo sozinhas e, assim, passam, também, a desenvolver equipes fortalecidas. As lideranças procuram contratar pessoas definitivamente melhores que eles, realizando uma atividade de fortalecimento, com o vislumbre de que sua equipe será a melhor possível e mais preparada para a prática da delegação. George (2009) complementa, ao afirmar que o processo de fortalecimento - tido, aqui, como o segundo pilar - está na prática de o líder cercar-se de pessoas competentes, inovadoras e criativas. A partir disso, dentro do contexto organizacional, fica evidente o que esperar de cada um, com essas novas habilidades e competências, visando à delegação e à descentralização do poder. Segundo D'Souza (1996), as lideranças, ao se preocuparem em não errar na tomada de decisão, acabam fracassando deliberadamente, desperdiçando muito tempo (nos mais diversos níveis) com a indecisão, denotando clara falta de um norte. Líderes ativos e eficazes procuram criar um norte para seus colaboradores de forma a construir um elevado nível de confiança, tornando comum a delegação de atividades relevantes.

O terceiro pilar está na atitude de servir aos seus clientes internos e externos e a todos os stakeholders, colaborando interna e externamente para a resolução de possíveis problemas. É um sentimento fundamental característico do perfil de um líder nato e promissor (GEORGE, 2009). A verdadeira forma de avaliar uma liderança não está no número de pessoas que lhe serve, mas, sim, o oposto. O líder tem essa atitude de servir em um primeiro plano e de ser líder no segundo. Trata-se de servir à missão da organização, e de todos os envolvidos, para a excelência dessa organização no mercado. Lideram servindo àqueles que estão na missão com eles, de forma a agregar significativo valor a todo o contexto empresarial em que tal companhia está inserida (MAXWELL, 2012). 
Nas organizações empresariais, diferentes tipos de líderes são necessários para diferentes tipos de situação, ainda que, independente do estilo adotado, exista a necessidade da colaboração mútua para que os propósitos comuns sejam atingidos (ERVILHA, 2008). Praticar o envolvimento de todos sobre o direcionamento de como trabalhar para fortalecer produtos e serviços aos clientes é uma das premissas básicas da liderança e, também, o quarto pilar. Isso, consequentemente, reflete-se em como as equipes colaboram entre si na solução de problemas comuns, com foco no mercado, facilitando o trabalho do gestor ao fazer com que todas as pessoas sintam-se parte dos processos-chave da organização, assim como responsáveis pelo desempenho organizacional (GEORGE, 2009).

Na concepção de George (2013), os líderes autênticos conhecem o seu norte verdadeiro, seus valores, suas paixões, suas motivações e suas fontes de satisfação são bem definidos. O líder consegue exercer liderança autêntica e as pessoas querem estar ao seu lado. Descobrir o norte verdadeiro é compromisso e aprendizado para a vida inteira. O líder precisa ser fiel à própria história de vida e aceitar-se como é, o que significa ser o mesmo no trabalho, em casa e na comunidade, de maneira a cuidar de si e das pessoas que considera importante. No entanto, a essência da liderança está em construir uma equipe ao redor de si e dar crédito a ela, alinhar os liderados em torno de um senso de propósito e estar ciente de que liderar significa servir o outro, e não ser servido. A ironia é que, quanto mais poder se tem, menos ele deve ser utilizado.

\subsection{Escassez de líderes no mercado}

Um dos maiores desafios da liderança contemporânea é de formar e manter uma equipe de alta performance. No entanto, sabe-se que o segredo da retenção desses talentos está em voltar o olhar para os membros dessa equipe e na liderança que a conduz. Líderes competentes têm em torno de si pessoas capazes de exercer a liderança quando necessário, além de criarem mecanismos, atitudes e posturas que estimulam o desenvolvimento de sucessores. Contudo, as empresas não conseguem formar líderes em quantidade e qualidade suficientes para se expandir ou se posicionar mais próximos de seus clientes e fornecedores, denotando uma escassez de líderes íntegros (SOUZA, 2008).

A falta de líderes preparados para enfrentar os novos tempos brasileiros é fato comprovado no dia a dia das empresas. Em uma pesquisa feita em 2011 pela Associação Brasileira de Recursos Humanos, em parceria com a consultoria Empreenda, dos 379 profissionais de recursos humanos entrevistados, 63,6\% disseram 
que suas empresas não contam com líderes suficientes para suprir as necessidades dos negócios, o que pode limitar o crescimento da organização durante a fase de expansão econômica do país (SHIOZAWA, 2013).

Nos últimos anos, as empresas focaram seus esforços em criar gerentes eficientes e não líderes eficazes. O que se vê, são chefes ocupando cargos de liderança, munidos de técnicas e ferramentas, porém incapazes de inspirar pessoas ou lidar com os potenciais conflitos que as características tão distintas entre as gerações $\mathrm{X}$ e Y podem gerar dentro das organizações (SOUZA, 2012).

Dentro desse contexto, é importante ressaltar que os cargos de liderança estão sendo ocupados por pessoas cada vez mais jovens e, na maioria das vezes, de forma despreparada. Comumente, as empresas acabam por alocar esses jovens em cargos estratégicos, sem que eles estejam devidamente capacitados. Esse fato pode gerar perdas significativas para a empresa, para o colaborador e para a equipe de trabalho.

\subsection{Desempenho empresarial}

Segundo Chiavenato (2012), o desempenho da organização está amarrado ao desempenho das pessoas, ao conhecimento retido por elas. O conhecimento não é apenas a nova moeda do capital intelectual, mas o núcleo do sucesso organizacional, principalmente para as empresas que sabem gerar, catalogar, divulgar, compartilhar e desenvolver o conhecimento. A abordagem não abrange somente essa competência durável que está na cabeça das pessoas, mas, sobretudo, o conhecimento que envolve todos os processos organizacionais e os relacionamentos da organização com seus stakeholders: clientes, fornecedores, parceiros, acionistas e, sobretudo, com gerentes e funcionários.

Percebeu-se, com o passar do tempo, que para haver uma boa liderança deve-se dar atenção à implementação de modelos de gestão que evidenciam a eficiência do recurso humano como forte componente da transformação e do desempenho organizacional. Tal evolução é abordada por Marins e Pasqual (2012) ao exemplificar que estratégias de gestão implantadas de forma apropriada ganham força ao tornarem-se sistemas geradores de inteligência de negócios a partir da gestão participativa das pessoas nos processos-chave, disseminando espírito intraempreendedor, ao mesmo tempo que dá autonomia aos participantes do sistema organizacional.

A tarefa constante da administração está em alinhar o desempenho organizacional com a qualidade de vida e a satisfação de seus colaboradores. Sabe-se que o desempenho empresarial está em primeiro plano, por ser o objetivo e a razão 
de ser da empresa. Porém, o desempenho não existirá, se o trabalho e o trabalhador forem mal geridos (DRUCKER, 2002). A maioria dos líderes trata as pessoas conforme a nota que eles mesmos atribuem a elas. Se um colaborador é avaliado por um gestor de forma mediana, esse mesmo gestor potencialmente lhe dará um tratamento mediano. Acredita-se que as pessoas têm valor como ser humano. O inter-relacionamento entre a liderança e o liderado aumenta significativamente as chances de o colaborador atender às expectativas do líder. Isso, logicamente, não significa recompensar o mau desempenho, mas, sim, agir corretamente e passar a adotar uma mentalidade de desenvolvimento. Tal mentalidade traz lucros maiores do que recorrer ao turnover dos que são avaliados como mais fracos na organização para, então, buscar pessoas no mercado para equiparar a organização (MAXWELL, 2012).

Conforme Hunt, Osborn e Schermerhorn (1998), para que uma equipe atinja o alto desempenho, a liderança tem de ser distribuída. Contudo, à medida que cada vez mais tarefas são delegadas, problemas específicos relacionados com os processos da equipe podem surgir. Por isso, a formação de uma equipe de alto desempenho é uma atividade dinâmica e contínua. É fato que grupos altamente coesos valorizam sua participação no contexto empresarial e procuram manter um relacionamento positivo com os demais integrantes da equipe. Em geral, equipes com essas características possuem menos rotatividade, maior segurança e estima. No moderno ambiente de trabalho, as palavras-chave para melhorar o desempenho organizacional são: participação, delegação e envolvimento.

\section{Metodologia}

O presente artigo trata de um estudo de caso único, de caráter exploratóriodescritivo, com pesquisa mista, levantamento de dados documentais e observação direta.

Este estudo foi realizado no grupo empresarial Surf Company Ltda., grupo empresarial varejista localizado no sul do país, especializado em moda jovem e artigos esportivos, tanto para iniciantes quanto para profissionais no esporte. Com constante foco na satisfação dos seus clientes, a Surf Company Ltda. preza por somente trabalhar com marcas renomadas e reconhecidas pelo consumidor, fortalecendo, assim, sua identidade na Serra Gaúcha. Os objetos desta pequisa são duas filiais, aqui designadas como General Sports Ltda. e General Surf Ltda. Com a finalidade de manter a identidade das companhias em sigilo e preservar seus diferenciais estratégicos, tanto às empresas quanto ao grupo empresarial ao qual 
pertencem foram atribuídos nomes fictícios, embora suas práticas estejam presentes nas diversas bibliografias ao alcance comum das comunidades acadêmica e empresarial.

Ainda que pertencentes ao mesmo grupo empresarial, as duas empresas concorrem entre si, disputando um espaço de destaque na região. Inaugurada há mais de dez anos, a General Sports Ltda. conta com 25 funcionários e mantém a posição de líder do mercado. No entanto, a General Surf Ltda., que conta com quinze colaboradores, embora com menos de um ano de vida, está aumentando seu desempenho em vendas, surpreendendo com resultados expressivos.

O levantamento dos modelos de gestão das empresas pertencentes ao grupo Surf Company Ltda., bem como dos aspectos culturais singulares da General Sports Ltda. e da General Surf Ltda., tiveram duas ênfases:

a) foram tratados como modelos de gestão, a relação de cada uma das empresas com os seus colaboradores do setor de vendas;

b) foram tratados como aspectos culturais singulares, a relação de cada uma das empresas com os seus clientes internos e externos.

As informações quantitativas sobre o nível de resposta às demandas dos clientes internos foram levantados nos setores de vendas de ambas as empresas, sendo que na General Sports Ltda. o levantamento corresponde aos períodos de junho de 2011 a maio de 2013, enquanto na empresa General Surf Ltda. o levantamento confere os períodos de junho de 2012 a maio de 2013. Esses foram os períodos comparativos utilizados como forma de análise dos modelos de gestão e do índice de turnover, conforme mostra o Quadro 3.

Quadro 3 - Amostra e período do levantamento dos dados da pesquisa

\begin{tabular}{|l|c|c|}
\hline \multicolumn{1}{|c|}{ Empresa } & General Sports Ltda. & General Surf Ltda. \\
\hline $\begin{array}{l}\text { Número de funcionários } \\
\begin{array}{l}\text { Período de levantamento } \\
\text { dos dados }\end{array}\end{array}$ & 25 & 15 \\
\hline
\end{tabular}

Fonte: elaborado pelos autores com base em dados da pesquisa.

Foram levantados os resultados financeiros das empresas filiais, o faturamento anual e o faturamento per capita, como forma de demonstrar o desempenho de cada uma das equipes nos seus respectivos modelos de gestão. Aqui o período analisado, para compatibilizar com a necessidade das informações anteriores, foi junho de 2010 a junho de 2011; de junho de 2011 a junho de 2012 e de junho de 2012 a maio de 2013. 
A técnica de observação direta não estruturada foi utilizada como forma de coletar dados mais fidedignos sobre os modelos de gestão adotados pelas empresas objeto deste estudo, mas que não são perceptíveis por meio dos dados quantitativos. Entre junho de 2012 e maio de 2013, foi possível analisar as práticas de liderança aplicadas pelos gestores em ambas as companhias estudadas, entre elas: atividades voltadas ao alinhamento de metas, estratégias organizacionais, integração de equipes, gestão participativa e operações cotidianas de trabalho. Tal técnica contribuiu para melhor compreensão do efeito das práticas de gestão em relação ao desempenho das equipes citadas no estudo de caso, tal como seus respectivos resultados.

\section{$4 \mathrm{O}$ modelo situacional e a construção de equipes de alto desempenho}

A General Sports Ltda., o primeiro case estudado, apresenta um modelo de gestão estável e mais alinhado com sistemas tradicionais da administração empresarial. É passível de observação um embasamento focado em muitos princípios tradicionais de gerenciamento, no qual o gestor volta-se para o controle operacional, a centralização no processo decisório, a especialização do capital humano, o exercício do "princípio da exceção", além da liderança baseada na tarefa e com pouca aproximação do time de liderados. Aplicando-se os elementos observados aos fundamentos da Teoria da Liderança Situacional, o que se percebe é um baixo comportamento de apoio e um alto comportamento diretivo. Segundo a abordagem em questão, isso ocorre quando o grau de maturidade dos liderados é muito baixo e há clara falta de confiança da equipe com relação à própria capacidade para realização das atividades. Esse estilo situacional, conhecido como M1E1, conforme pode ser visualizado na Figura 2, pressupõe que o líder delegue e acompanhe de perto a execução até que os colaboradores sintam-se confiantes para desempenharem suas tarefas sozinhos. 
Figura 2 - O modelo da Liderança Situacional aplicado às empresas General Sports e General Surf

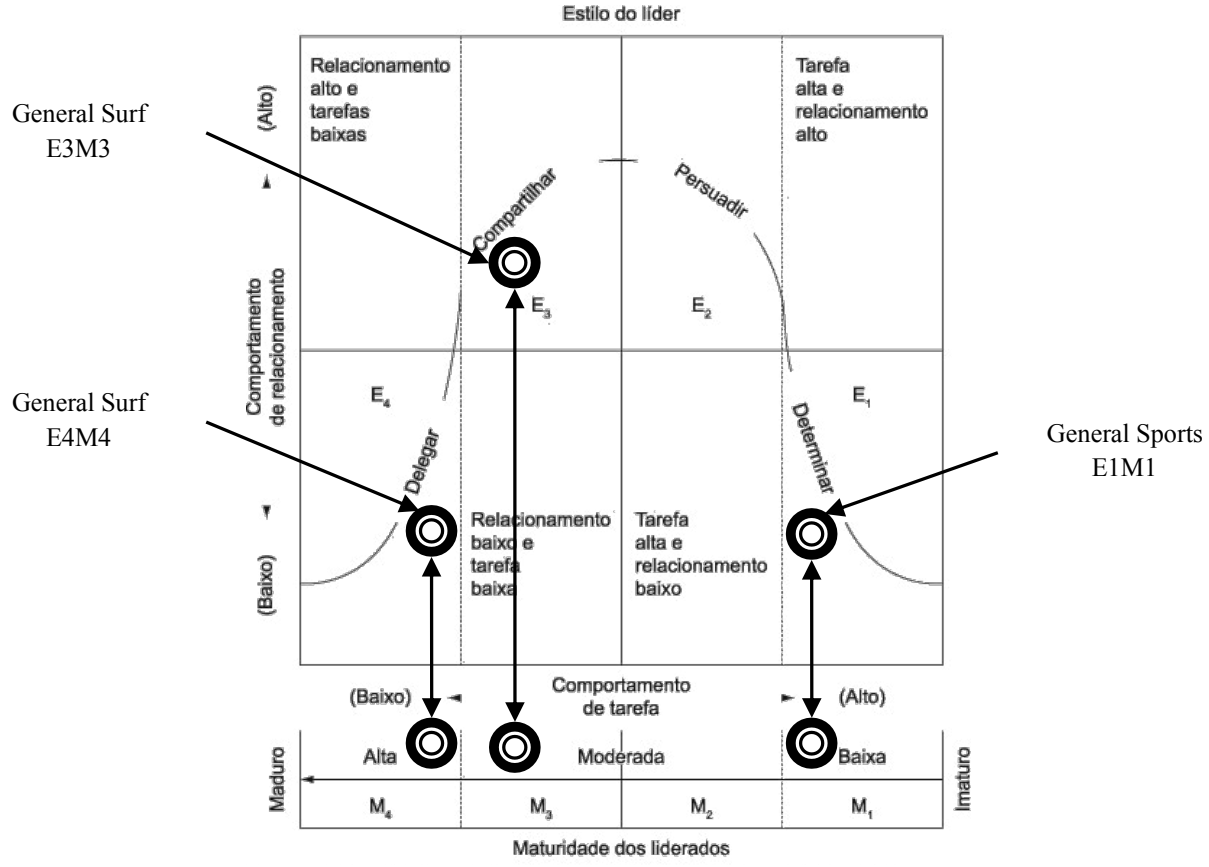

Fonte: elaborado pelos autores com base em Hersey e Blanchard, 1986.

Em contrapartida, a General Surf Ltda., segundo case estudado, apresenta um modelo de gestão mais evoluído. Trata-se de uma dinâmica que visa à eficiência coletiva por meio da captação e utilização do potencial máximo de cada colaborador e conta com práticas mais interativas entre liderança e liderados. Isso significa incluir as pessoas no processo decisório, integração coletiva do intelecto individual nos processos-chave da organização, multifuncionalidade e alto nível de aproximação entre líder e liderados.

Percebe-se variação entre baixo e o alto comportamento de apoio e um baixo comportamento diretivo (Figura 2). De acordo com a Teoria da Liderança Situacional, esse é o modelo adequado, quando o grau de maturidade dos liderados é elevado, atingindo o M4. São considerados apropriados, nesse caso, os estilos de compartilhamento (E3) e delegação (E4). Essa variação tende a perdurar, uma vez que a teoria preza pela contribuição da liderança no desenvolvimento do amadurecimento do liderado. 
Devido ao curto tempo de existência da equipe dessa empresa, um estilo participativo (E3) ajuda na construção da autoconfiança e na motivação, fazendo com que todos tenham uma participação ativa em todo o processo decisório. Logo, a liderança atua como um facilitador, fazendo a gestão direta por meio do relacionamento e da comunicação disseminada.

Isso condiz com um dos objetivos das reuniões de gestão, tradicional ferramenta de comunicação: fazer um direcionamento com relação ao planejamento estratégico da organização, para que, assim, as pessoas compreendam o impacto de sua atividade com os objetivos estratégicos da organização. Esse alinhamento é importante na gestão participativa, pois os liderados vivenciam os valores da organização e percebem a importância que possuem como colaboradores.

Além de identificar quando precisa estimular os seus colaboradores, dando o apoio emocional e a motivação necessária para que consigam obter um melhor desempenho, o perfil da liderança da General Surf Ltda., conhecedor de sua própria equipe, prima pela manutenção e direcionamento do capital intelectual, desenvolvendo constantemente as habilidades e competências duráveis das pessoas que compõem seu time. Esse trabalho de fortalecimento prepara as pessoas para que $o$ estilo de liderança possa migrar para E4, descentralizando o poder e aumentando o potencial para novos desafios e a delegação de atividades com maior valor agregado. O gestor observa as competências, as habilidades, a motivação, a eficiência e eficácia de cada colaborador. O foco é promover a correta alocação do recurso humano a fim de se extrair o melhor de cada um.

\subsection{A dinâmica dos modelos de gestão e seu impacto no desempenho organizacional}

De acordo com os dados levantados, nos últimos dois anos, a General Sports Ltda. aplicou alterações na maior parte da equipe de vendas. É preciso evidenciar que durante todo esse período a empresa esteve sob a gerência da mesma liderança, que assumiu a equipe em 2010. Com base na Teoria da Liderança Situacional, o alto grau de rotatividade aumenta o grau de criticidade quanto à tendência de baixa maturidade no presente modelo de gestão. $\mathrm{O}$ indicador apresentado na Figura 3 mostra que há falta de continuidade em $88 \%$ da equipe. Isso significa que há um número muito baixo de colaboradores em continuidade no grupo. Nesse caso, apenas $12 \%$ da equipe se mantêm inalterada por um período superior a um ano. Esse alto índice de turnover apresentado condiciona a equipe a um ciclo constante 
de aprendizado básico das atividades diárias. Essa dificuldade de evolução mantém esse time estático e em ciclo contínuo de estagnação, não possibilitando o crescimento individual gradual e a capacidade para assumir novas responsabilidades.

Figura 3 - Índice de turnover na General Sports Ltda. - 2011 a 2013

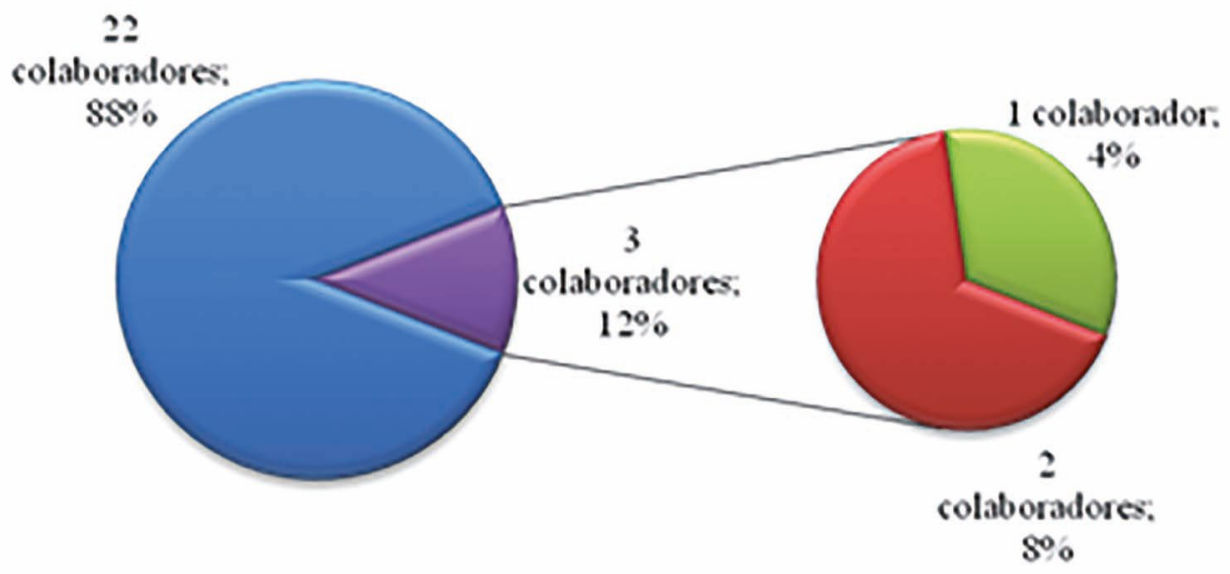

$\square$ Menos de 1 ano $\square$ Entre 1 e 2 anos $\square$ Acima de 2 anos

Fonte: elaborada pelos autores com base em dados da pesquisa.

O baixo grau de relacionamento do modelo de gestão da General Sports Ltda. aponta uma organização com estrutura mais rígida e hierarquizada, em que a relação de confiança e poder está muito vinculada à prerrogativa do cargo e pouco nas relações interpessoais. Entendendo que a confiança é construída ao longo do tempo e de forma legítima, a realidade organizacional acaba sendo fortemente afetada por diferentes aspectos na relação da liderança com os liderados. Nesse cenário, os colaboradores possuem pouca voz ativa nos processos decisórios ou nos processos-chave da empresa, o que acaba diminuindo as expectativas positivas da equipe com relação à organização e à credibilidade do líder bem como influenciando negativamente no grau de comprometimento do time para com as metas estratégicas da empresa e com a manutenção da carteira de clientes. O reflexo disso é um contexto organizacional com um modelo de gestão extremamente centralizador. Embora o comportamento mais diretivo do líder objetive aumentar a produtividade do liderando, isso induz a uma insegurança por parte da equipe quanto a sua própria competência para com o desempenho das tarefas, conduzindo todos os envolvidos a um clima organizacional desfavorável. 
Com relação à General Surf Ltda., ao longo do período pesquisado, foi possível observar práticas em que a liderança objetivou maior integração entre as pessoas, incentivando-as a serem criativas, inovadoras e a buscarem soluções para o alcance de metas. Tais métodos oportunizaram o rápido amadurecimento da equipe e o alto grau de comprometimento com os objetivos organizacionais. As boas práticas de liderança são o alicerce da gestão nesta empresa e seu comandante tem plena consciência de que cada colaborador é singular e, portanto, deve ser tratado como tal.

Um dos reflexos desse modelo de gestão está no indicador de turnover da empresa. Ainda que se trate de uma empresa com pouco menos de um ano de existência no mercado, percebe-se que entre funcionários que compõem a equipe de vendas (quinze), 86,67\% permanecem inalterados e que apenas 13,33\% da equipe (dois integrantes) tiveram modificações nesse período (Figura 4).

Figura 4 - Índice de turnover na General Surf Ltda. - 2012 a 2013

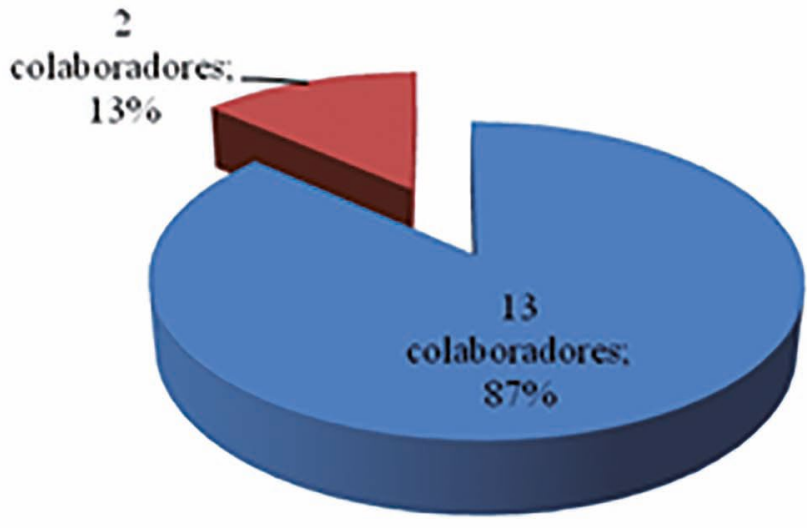

\section{aPemanc̀ncia de 1 ano $\quad$ Menos de 1 ano}

Fonte: elaborada pelos autores com base em dados da pesquisa.

Se comparadas, ambas empresas, considerando-se apenas os últimos doze meses deste estudo, pode-se dizer que as duas equipes são novas. Contudo, ao analisar-se a Figura 5, constata-se que a General Sports Ltda. mudou 100\% de seu time de vendas, enquanto que a General Surf Ltda. mantém o mesmo turnover de $13,33 \%$. 
Figura 5 - Índice de turnover comparativo entre as empresas General Sports e General Surf junho de 2012 até maio de 2013

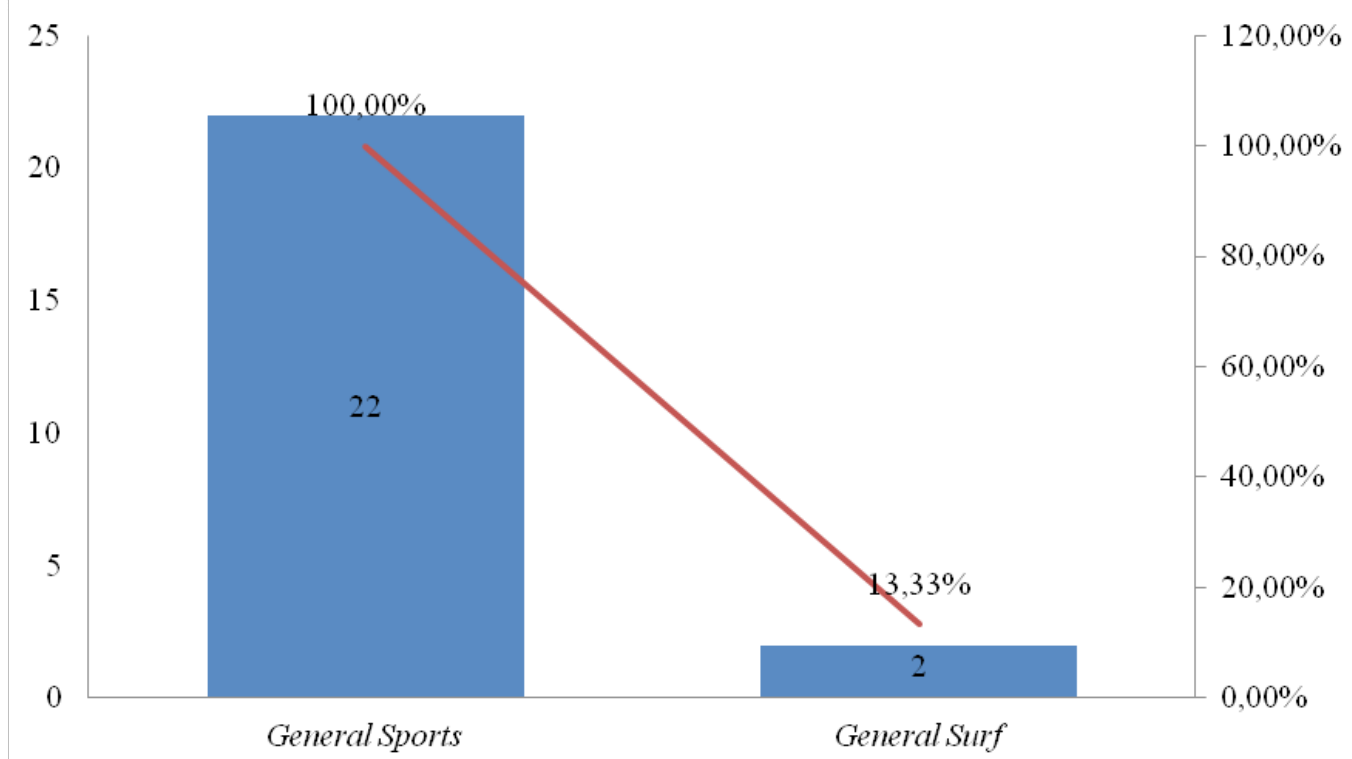

Fonte: elaborada pelos autores com base em dados da pesquisa.

A forte tendência de continuidade, devido ao grau de maturidade atingido pela equipe de vendas da General Surf Ltda. e ao modelo de gestão construído com forte base na delegação, confiança e processo decisório participativo, possibilita a esse time um ciclo de aprimoramento das habilidades e um ciclo evolutivo das competências duráveis de um profissional. A criação e a manutenção da equipe de alto desempenho passou, basicamente, neste estudo, por todos os Quatro Pilares da Liderança. Com o alinhamento em relação ao "norte organizacional", as pessoas vivenciam a missão, a visão e os valores da empresa. Combinado com o fortalecimento das equipes, o líder passa a ter menos necessidade em exercitar o poder formal e fazer o controle das atividades. Ao dar crédito e delegação, pelo fortalecimento, a descentralização do poder faz com que as pessoas sintam-se importantes e valorizadas, mantendo-se seguidores dessa liderança. Consequentemente, as pessoas mantêm-se preparadas para o processo de fortalecimento de produtos e serviços oferecidos aos clientes. Esse fator relevante é traduzido em números acima da média esperada, conquistando espaço em seu mercado de atuação, fidelizando os clientes internos e externos, devido ao atendimento diferenciado e aos gestores capacitados. 
Partindo do pressuposto de que os fatores abordados anteriormente estão diretamente relacionados ao alcance dos objetivos organizacionais, consequentemente, de seus resultados financeiros, verificou-se que, no tocante ao faturamento das empresas, a General Sports Ltda., nos últimos três anos, sofreu uma redução significativa. Cabe destacar que essa empresa conta com um número significativo de clientes fidelizados e está em um dos melhores pontos de venda da região onde está instalada, porém, essas vantagens competitivas não estão sendo suficientes para frear a perceptível redução nos resultados financeiros advindos das atividades da equipe de vendas. Analisando o faturamento dos últimos três anos (Quadro 4), percebe-se que de junho de 2010 a junho de 2011, a empresa obteve um faturamento de R \$4.650.000,00. No ano seguinte, ou seja, junho de 2011 a junho de 2012 a General Sports Ltda. faturou $R \$ 4.300 .000,00$. De junho de 2012 a maio de 2013, o faturamento alcançado foi de $\mathrm{R} \$ 3.600 .000,00$. O indicador mostra que, de um ano para o outro, houve uma redução nos resultados financeiros de 7,53\% e 16,28\%, respectivamente. Considerando, o primeiro e o terceiro anos, pode-se notar que houve uma queda significativa nos resultados de faturamento, chegando a $22,58 \%$. Se analisado somente o último ano, verifica-se que o resultado per capita gira em torno de $\mathrm{R} \$ 144.000,00$ para cada integrante do grupo, o que leva a um resultado médio mensal por integrante de $\mathrm{R} \$ 12.000,00$.

Quadro 4 - Resultados de faturamento das empresas

\begin{tabular}{|c|c|c|c|c|}
\hline Empresas & Período analisado & Faturamento anual & $\begin{array}{c}\text { Número de } \\
\text { colaboradores }\end{array}$ & $\begin{array}{c}\text { Resultado } \\
\text { per capita }\end{array}$ \\
\hline \multirow{3}{*}{ General Sports } & jun. 2010/jun. 2011 & $\mathrm{R} \$ 4.650 .000,00$ & 25 & $\mathrm{R} \$ 186.000,00$ \\
& jun. 2011/jun. 2012 & $\mathrm{R} \$ 4.300 .000,00$ & 25 & $\mathrm{R} \$ 172.000,00$ \\
& jun. 2012/maio 2013 & $\mathrm{R} \$ 3.600 .000,00$ & 25 & $\mathrm{R} \$ 144.000,00$ \\
\hline General Surf & jun. 2012/maio 2013 & $\mathrm{R} \$ 2.750 .000,00$ & 15 & $\mathrm{R} \$ 183.333,33$ \\
\hline
\end{tabular}

Fonte: elaborada pelos autores com base em dados da pesquisa.

Percebe-se então que, em decorrência dos fatores organizacionais já relacionados, a General Sports Ltda. está enfrentando perda do seu capital intelectual. A mão de obra, nesse caso, é capacitada e depois devolvida ao mercado, basicamente sendo absorvida pela concorrência ou outros segmentos do mercado, impactando claramente na parte financeira da empresa.

Em contrapartida, a General Surf Ltda. está aumentando consideravelmente o seu desempenho em vendas. No período de junho de 2012 até maio de 2013, a empresa obteve um faturamento de $R \$ 2.750 .000,00$. O resultado per capita indica que, no período analisado, cada integrante da equipe vendeu uma média 
de $\mathrm{R} \$ 183.333,33$. Pode-se dizer que essa empresa teve um resultado per capita $\mathrm{R} \$ 39.333,33$, número superior a General Sports Ltda. no mesmo período.

Conforme já citado por Bergamini (1994) no item 2.2 deste artigo, a liderança é estudada como um processo de interação que envolve trocas sociais. Segundo a mesma autora, a influência que pode exercer um líder melhor fluirá a partir do conhecimento que ele tem da própria equipe. Isso o torna um facilitador para o atingimento de objetivos individuais e coletivos. Tonet et al. (2012) complementam, apontando que a liderança, ao estabelecer um comportamento de apoio, acaba por exercer uma influência positiva de modo a promover um alinhamento dos objetivos pessoais com os organizacionais, conduzindo, assim, as equipes ao sucesso.

Com base em tais afirmações, pode-se dizer que, nesse caso, a retribuição da equipe é o pleno entendimento sobre as responsabilidades individuais nas metas coletivas, facilitando o papel da liderança ao torná-lo mais um coaching do que propriamente a figura do chefe formal posicionado na ponta do organograma. A integração e o envolvimento das pessoas permitem que a General Surf Ltda. torne-se uma organização que aprende. Um dos princípios básicos de funcionamento dessa equipe é a disseminação do conhecimento, resultando na construção de uma identidade competitiva reconhecida pelos clientes, assim como uma linguagem comercial única para atingir o mercado.

O modelo situacional culmina com a sistemática aplicada na segunda empresa estudada. Atuar como coaching, dar feedback construtivo, manter o clima de cooperação interna e estabelecer metas individuais, sem tirar os olhos dos objetivos estratégicos, foi um passo importante na alocação eficiente das pessoas, dando espaço para que elaspudessem atuar dentro daquilo que fazem de melhor. Dessa forma, o indivíduo mantém um canal aberto para a aprendizagem, oportunizando mudanças no comportamento e estímulo ao autodesenvolvimento.

Esse ambiente proporciona as condições ideais para o crescimento individual que resultará no comprometimento coletivo no cumprimento das metas organizacionais.

\section{Considerações finais}

No decorrer da pesquisa, evidenciou-se que, apesar de ambas empresas pertencerem ao mesmo grupo empresarial, os modelos de gestão e os indicadores de desempenho das empresas objeto do presente estudo são completamente antagônicos. O modelo de gestão apresentado pelo primeiro case revelou impactos negativos no seu grupo de trabalho bem como nos resultados financeiros da empresa. 
A empresa General Sports Ltda., nos últimos dois anos, apresentou alto índice de turnover bem como uma redução significativa em seus resultados financeiros. Essa redução no faturamento diz respeito à conjuntura econômica mundial e à perda de seus clientes internos e externos para as empresas concorrentes, dentre elas, a própria General Surf Ltda.. O modelo de comando e de controle utilizado pela liderança da empresa General Sports Ltda. (E1M1), de acordo com a Teoria da Liderança Situacional, é consequência da evidente falta de maturidade da equipe. Situacionalmente, o líder dessa empresa é conduzido a um comportamento de gestão mais tradicional, voltado às atividades e menos ao relacionamento. Tal falta de maturidade e de comportamento de gestão, conforme já foi abordado pelos autores anteriormente citados, tem um impacto direto no desempenho. O reflexo disso pode ser visto nos indicadores da General Sports Ltda. apontados neste estudo, uma vez que há queda nas vendas e índices elevados de turnover.

Em contrapartida, a empresa General Surf Ltda. evidenciou impactos positivos na performance de sua equipe, fidelizando clientes internos e externos e alcançando números acima da média esperada. A preocupação desse líder é servir e tornar a sua equipe mais confiante, assertiva, eficiente e eficaz afim de que possa melhor desempenhar seu papel em situações de adversidade e estresse - explicando, assim, o baixo índice de rotatividade na empresa em questão. O alicerce dessa gestão é a utilização da Liderança Situacional e dos Quatro Pilares da Liderança. O líder da empresa General Surf Ltda. transmite segurança aos seus liderados, pois utiliza três práticas de suma importância: feedback adequado à sua equipe e na frequência apropriada, compartilha a missão, visão e valores da empresa e incentiva o empowerment. Tais atitudes, fundamentais para o exercício da liderança - conforme já apresentado nas bibliografias pertinentes -, contribuem para o amadurecimento da equipe, permitindo ao líder comportamentos de relacionamento voltados ao compartilhamento do conhecimento e à delegação das atividades - o que, segundo a Teoria da Liderança Situacional, configuram-se como E3M3 e E4M4, respectivamente.

Com base nos resultados apresentados, a adoção do modelo de Liderança Situacional permitiu identificar aspectos direcionadores do comportamento de gestão de ambas as lideranças, contudo vale ressaltar que a percepção do gestor da General Surf Ltda. foi melhor sucedida por buscar comportamentos muito mais voltados à construção da maturidade do time do que propriamente à tarefa. Nesse caso, as práticas de empoderamento, alinhamento estratégico, capacitação e colaboração pilares essenciais da liderança do século XXI - contribuíram para minimização de impactos negativos nos indicadores de desempenho bem como para o aumento da eficiência e eficácia da equipe. 
Embora este trabalho seja um estudo de caso único, torna-se relevante dizer que o modelo de Liderança Situacional é aplicável em qualquer organização que apresente características similares. Cabe salientar que tudo vai depender do nível de maturidade do gestor e de seus liderados bem como do ambiente em que estiverem inseridos.

Portanto, pode-se concluir que a Liderança Situacional e os Quatro Pilares da Liderança foram de suma importância para a construção e manutenção de equipes de alto desempenho. A nova liderança do século XXI precisa aplicar eficazmente essas duas ferramentas e praticar a gestão sustentável, ou seja, promover o desenvolvimento das pessoas que estão à sua volta, zelando pelos valores da organização sem perder o foco nos resultados. A proatividade por parte do líder é outro fator importante, pois ele deve servir de exemplo a seus liderados. Além dessa disposição para a ação, o líder precisa manter o foco e o equilíbrio emocional, a fim de alocar corretamente os seus liderados, pois se eles não estiverem confortáveis na posição em que se encontram, fatalmente não conseguirão ser proativos.

Por fim, o líder do século XXI deve ser autêntico e conhecer o seu norte verdadeiro. Ele precisa ser fiel aos seus valores, às suas crenças e às suas paixões; não deve corromper-se diante de situações adversas, deve ser ele mesmo, sempre. O verdadeiro líder precisa alinhar, capacitar, servir, colaborar, encorajar, desenvolver, ter diálogo franco e honesto com seus liderados; tornar a equipe mais afetiva, pois somente assim terá uma equipe unida e engajada para o alcance dos objetivos organizacionais. 


\title{
The pillars of leadership and the situational model: the leader's influence in the hight performance teams formation and its results
}

\begin{abstract}
The objective of this article is identifying the leadership models used by companies General Sports Ltda. and General Surf Ltda., based on the Situational Leadership Theory and Four Pillars of Leadership, such as establishing a comparison between the effects from such models to finally analyze the impact of how different forms of leadership can influence on organizational results and performance of their teams. Thereunto, the methodology used was case study divided in three stages: direct observation and classification of leadership model applied by each of the sales managers of companies in the Situational Leadership Theory; the documentary analysis of the financial results and turnover rates of the their teams; and finally, a comparison between the companies for both performance indicators. As the main results, it can be seen that the traditional management model, based on command and control model, was responsible for the increase turnover rate and the reduction of the financial results of General Sports Ltda. In another way, it was found that leadership practices aimed to knowledge sharing and activities delegation, both used by General Surf Ltda., allowed organizational and individual performances increase.
\end{abstract}

Keywords: Situational Leadership. Four Pillars of Leadership. High performance teams.

\section{Los pilares del liderazgo y modelo situacional: la influencia del lider en la formación de equipos de alto desempeño y sus resultados}

\section{Resumen}

El objetivo de este artículo es identificar los principales modelos utilizados por las compañías General de Sports Ltda. y General Surf Ltda., basado en la Teoría de Liderazgo Situacional y los Cuatro Pilares del Liderazgo, tal como estabelecimiento de una comparación entre los efectos destes modelos para analizar finalmente el impacto de cómo las diferentes formas de liderazgo puedem influir en los resultados de la organización y el desempeño sus equipos. Para eso, la metodología utilizada fue un estudio de caso dividido en tres etapas: la observación directa y la clasificación de modelo de liderazgo aplicado por cada uno de los gerentes de ventas de las empresas en la Teoría del Liderazgo Situacional; el análisis documental de los resultados financieros de las tasas de rotación de sus equipos; y finalmente, una comparación entre las empresas en estudio para ambos indicadores. Como principales resultados se pueden ver que el modelo tradicional de liderazgo basado en modelo de mando y control, fue responsable del aumento en la tasa de rotación y la reducción de los resultados financieros de General Sports Ltda. En contraste, se encontró que las prácticas de liderazgo destinados a compartir el conocimiento y la delegación de actividades, adoptadas por la General Surf Ltda., permiten un aumento en el rendimiento de la organización y el individuo.

Palabras clave: Liderazgo Situacional. Cuatro Pilares de Liderazgo. Equipos de alto rendimiento. 


\section{Referências}

BERGAMINI, Cecília Whitaker. Liderança: a administração do sentido. Revista de Administração de Empresas, São Paulo, v. 34, n. 3, p. 102-114, maio/jun. 1994.

BLANCHARD, Ken. Liderança de alto nível: como criar e liderar organizações de alto desempenho. São Paulo: Bookman, 2007.

CASTRO, Alfredo. Métodos de liderança devem ser revistos com as mudanças no mercado de trabalho. 2013. Disponível em: <http://revista.penseempregos.com.br/noticia/2013/04/metodos-de-lideranca-devem-ser-revistos-com-as-mudancas-no-mercado-de-trabalho-4096991.html>. Acesso em: 11 abr. 2013.

CHIAVENATO, Idalberto. Gerenciando com as pessoas: transformando o executivo em um excelente gestor de pessoas. Rio de Janeiro: Elsevier, 2005.

. Administração geral e pública. Rio de Janeiro: Elsevier, 2006.

. Gestão de pessoas: o novo papel dos recursos humanos nas organizações. Rio de Janeiro: Elsevier, 2008.

. Teoria geral da administração. Rio de Janeiro: Elsevier, 2011.

. Construção de talentos: coaching \& mentoring. Rio de Janeiro: Elsevier, 2012.

COVEY, Stephen R. Liderança baseada em princípios. Rio de Janeiro: Campus, 1996.

DALMAN, Marcos Baptista Lopez; TOSTA, Cristina Benetti Tonani. Estratégia de pessoas. Curitiba: IESDE Brasil, 2009.

DRUCKER, Peter. Fator humano e desempenho: o melhor de Peter F. Drucker sobre administração. São Paulo: Pioneira Learning Thomson, 2002.

D’SOUZA, Anthony. Torne-se um líder: estratégias para uma liderança efetiva. São Paulo: Loyola, 1996.

ERVILHA, Antõnio de Jesus Limão. Liderando equipes para otimizar resultados. 3. ed. São Paulo: Nobel, 2008.

FRANCO, José de Oliveira. Recursos humanos: fundamentos e processos. Curitiba: IESDE, 2008.

FUHRMEISTER, Carolina L. O segredo das equipes de alta performance. 2011. Disponível em: <http://equilibriumrh.com.br/o-segredo-das-equipes-de-alta-performance>. Acesso em: 21 abr. 2013.

GEORGE, Bill. Liderança autêntica: resgate os valores fundamentais e construa organizações duradouras. São Paulo: Gente, 2009.

A década perdida da liderança. Revista HSM Management, São Paulo, a. 16, v. 7, n. 96, p. 98-100, jan./fev. 2013.

GOLEMAN, Daniel. Liderança que traz resultados. Revista Harvard Business Review Brasil, v. 88 , n. 10 , p. $76-77$, out. 2010.

HHERSEY, Paul; BLANCHARD, Ken. Psicologia para administradores: a teoria e as técnicas da liderança situacional. São Paulo: Editora Pedagógica e Universitária, 1986. 
HUNT, James G; OSBORN, Richard N; SCHERMERHORN, John R. Fundamentos de comportamento organizacional. São Paulo: Bookman, 1998.

KOTTER, John P. Liderando mudança. Tradução de Follow-up Traduções e Assessoria em Informática. 17. ed. Rio de Janeiro: Elsevier, 1997.

MARINS, Márcio; PASQUAL, Cássia Aparecida. Lean Thinking: um estudo sobre a jornada rumo à implementação do conceito de lean supply chain management. Revista Mundo Logística, Curitiba, v. 26, p. 24-37, 2012.

MAXIMIANO, Antonio C. A. Teoria geral da administração: da revolução urbana à revolução digital. São Paulo: Atlas, 2005.

MAXWELL, John C. O líder $360^{\circ}$ : como desenvolver seu poder de influência a partir de qualquer ponto da estrutura corporativa. 2. ed. Rio de Janeiro: Thomas Nelson Brasil, 2012.

NOVO, Damáris Vieira; CHERNICHARO, Edna de Assunção Melo; BARRADAS, Mary Suely Souza. Liderança de equipes. Rio de Janeiro: FGV, 2008.

SANTOS, Angélica Alves et al. Liderança: uma abordagem prática. Andradina, 2013.

SHIOZAWA, Ruy. O RH e a escassez de líderes. Pessoas de ValoRh, São Paulo, a. 26, n. 1.263, 2013. Disponível em: <http://www.abrhrj.org.br/typo/fileadmin/user_upload/ABRHNACIONAL/ ABRH-Nacional_31_01_2013.pdf>. Acesso em: 5 maio 2013.

STEPANSKI, Isabel; COSTA, Maria Eugênia. Aspectos comportamentais de gestão de pessoas. Curitiba: IESDE do Brasil, 2012.

SOUZA, Cesar. Os Segredos do Líder Inspirador. In: MAGALHÃES, Dulce (Org.). Pensamento Estratégico para Líderes de Hoje e Amanhã. São Paulo: Integrare Editora, 2008.

TONET, Helena Correa et al. Liderança e gestão de pessoas em ambientes competitivos. Rio de Janeiro: FGV, 2012.

ULRICH, Dave. Marca da liderança. Revista HSM Management. Direto ao ponto: Alta gerência. Ano 14. Edição 79, v. 2, p. 14, mar./abr. 2010. 